\title{
Harmonization of the assessment method for classifying the ecological quality status of very large Greek rivers
}

\author{
Maria Lazaridou, ${ }^{1, *}$, Chrysoula Ntislidou ${ }^{1,2}$, Ioannis Karaouzas ${ }^{2}$, Nikolaos Skoulikidis $^{2}$ and \\ Sebastian Birk ${ }^{3,4}$ \\ ${ }^{1}$ Department of Zoology, School of Biology, Faculty of Sciences, Aristotle University of Thessaloniki, Anavissos, Greece \\ 2 Institute of Marine Biological Resources and Inland Waters, Hellenic Centre for Marine Research, 46.7 km Athens-Sounio Av., 19013, \\ Anavissos, Greece \\ ${ }^{3}$ Department of Aquatic Ecology, Faculty of Biology, University of Duisburg-Essen, Universitätsstrasse 5, 45141 Essen, Germany \\ ${ }^{4}$ Centre for Water and Environmental Research, University of Duisburg-Essen, Universitätsstrasse 5, 45141 Essen, Germany
}

\begin{abstract}
The intercalibration exercise is required by the European Water Framework Directive (WFD) to harmonize the national ecological class boundaries across Member States. It is applied to individual types of water bodies, comparing WFD-compliant biological assessment methods using specific quality elements. This study addresses the harmonization of the STAR ICMi index for the ecological status assessment of very large Greek rivers in compliance with the completed intercalibration exercise for European very large rivers. River sites were sampled biannually for benthic invertebrates (as biological quality element) and environmental data during different surveys. The water quality of the samples ranged from high to bad. STAR_ICMi was significantly correlated to the Combined Abiotic Pressure index (CAPi) and its component pressures channelization, riparian vegetation alteration, and to a lesser extent to organic pollution. During the intercalibration approach benchmark standardization was applied to the component metrics of the intercalibration index prior to boundary comparison to minimize typological differences. The Greek class boundaries of high/good and good/moderate ecological status were compared and harmonized with the "Global Mean View" defined in the completed European intercalibration exercise. Similarity percentage analysis of biological community variation was performed for sites in high, good, and less than good ecological status according to the intercalibrated Greek classification.
\end{abstract}

Keywords: benthic invertebrates / intercalibration / monitoring / ecological status / class boundaries

Résumé - Harmonization de l'indice pour classifier l'état écologique des grands cours d'eau grecs: La pratique de l'intercalibration est requise par la directive-cadre Européenne sur l'eau afin d'harmoniser les limites écologiques nationales entre les Etats membres. Ce critère est appliqué à différents types de masses d'eau, en comparant les méthodes d'évaluation biologique conformes à la DCE utilisant des éléments de qualité spécifique.

Cette étude porte sur l'harmonisation de la STAR_ICMI (indice pour évaluer l'état écologique des grands cours d'eau grecs) conformément à l'intercalibration déjà réalisée pour de très grandes rivières Européennes. Deux fois par an, les sites ont été échantillonnés pour les invertébrés benthiques (comme éléments de qualité biologique) et les données environnementales ont été relevées. La qualité de l'eau variait entre la meilleure et la moins bonne. Le STAR_ICMI était significativement corrélé à l'indice de pression combinée abiotique (ICPA) et sa composante pression de canalisation, à la modification de la végétation riveraine et, dans une moindre mesure, à la pollution organique. Pour minimiser les différences typologiques, avant la comparaison des limites des classes de statut écologique (meilleure/bonne, bonne/ moyenne) une normalisation de référence a été appliquée aux mesures de l'Indice commun d'Intercalibration; ensuite, les limites étaient aussi comparées et harmonisées avec la « vision globale moyenne » enregistrée dans l'intercalibration déjà réalisée. La variation de la communauté biologique pour

\footnotetext{
*Corresponding author: mlazarid@bio.auth.gr
} 
les classes grecques (excellent, bon, moins que bon) a été étudiée avec l'analyse de pourcentages de similarité.

Mots-clés : invertébré benthique / intercalibration / monitoring / statut écologique / limites de classes

\section{Introduction}

The Water Framework Directive (WFD; 2000/60/EC) is widely accepted as the most ambitious European environmental legislation by integrating all aspects for the protection of surface waters (rivers, lakes, transitional, and coastal waters) and the objective to achieve good ecological status or potential by 2015 . However, its implementation has proven problematic as all Member States (MSs) are required to achieve the WFD environmental objectives by the end of the second and third management plans, which extend from 2015 to 2021 and 2021 to 2027, respectively (EC, 2012). Among other requirements, the intercalibration (IC) exercise is one of the most challenging as it has to ensure common understanding of "good ecological status" across MSs (EC, 2005; Birk et al., 2013), considering only assessment methods that meet the requirements of the WFD (EC, 2011). The IC exercise was performed by comparing the national assessment methods, by means of a common metric, and harmonizing their high-good (HG) and good-moderate (GM) boundaries of ecological status, separately for individual water bodies types and biological quality elements (BQEs) (e.g., EC 2005; Birk et al., 2006; Buffagni et al., 2006; Buffagni et al., 2007; Erba et al., 2009; Bennett et al., 2011; EC 2011). This exercise is still ongoing for some $\mathrm{BQEs}$ and water body types for a number of MSs.

Very large rivers (catchment area $>10,000 \mathrm{~km}^{2}$ ) have recently been intercalibrated for 16 national assessment methods using benthic invertebrates (XGIG IC exercise; Birk et al., 2016). This IC exercise was based on sampling data covering the main channel habitats of 279 water bodies at very large rivers across Europe, comprising (i) the demonstration of pressure-response relationships and WFD-compliance of the national assessment methods participating in the exercise, (ii) the assessment of ecological status in the absence of a typological differentiation applying "benchmark standardization" against the Combined Abiotic Pressure index (CAPi), and (iii) the comparison and harmonization of the national class boundaries of good ecological status.

Key of the IC exercise was to design a biological index that allowed for comparing the national status classifications, the so-called Intercalibration Common Multimetric index (IC index) for very large rivers. The IC index consists of six single biological assessment metrics, which translate the national (often multimetric) assessments into an "international currency" (Birk et al., 2013). The IC index addresses all biological parameters relevant for WFD-compliant ecological status classification using benthic invertebrates (EC, 2000 Annex V), i.e., taxonomic composition, abundance and diversity, disturbance sensitive taxa to insensitive taxa, and all major taxonomic groups.

Greece, among other countries, did not participate in the IC exercise for benthic invertebrates in very large rivers because its national assessment method was still under development when the exercise was performed. This article deals with the later IC of the newly developed Greek method, outlining the data basis that underlies the necessary analyses for method development, including the international IC data to align the classification of good ecological status. Furthermore, the key features of the Greek method to comply with the requirements of the WFD are addressed, comprising (i) validated pressureresponse relationships, (ii) its classification related to nearnatural reference conditions, and (iii) the setting of five classes of ecological status. The latter point required an alignment of good status to the outcomes of the IC exercise (EC, 2015; Birk et al., 2016). The necessary steps in this procedure are documented concerning (i) the computation of CAPi and IC index, (ii) the benchmark standardization, (iii) the fitting of the Greek boundaries of good ecological status to the IC results, and (iv) the description of the invertebrate communities characteristic of Greek very large rivers at high, good, and moderate (or worse) ecological status.

\section{Materials and methods}

\subsection{Available data}

\subsubsection{Greek database}

Data of 113 benthic invertebrate and water samples belonging to 53 sites from very large Greek rivers were collated (Fig. 1). Sites were sampled up to six times during different surveys between 1995 and 2015. The water quality of the samples were pre-evaluated from "high" to "bad" according to the existing Hellenic Evaluation System (Artemiadou and Lazaridou, 2005; HESY) for other river types. The Greek environmental data (e.g., river name, national river type, altitude, upstream catchment area, latitude, longitude, and discharge) and biotic (benthic invertebrates) data were collected in the framework of the National Monitoring Program and research projects of the Aristotle University of Thessaloniki.

Samplings were generally conducted biannually during the high (spring) and low (summer or autumn) flow periods at accessible microhabitats of both river banks or/and from the riverbed if its depth was $<1 \mathrm{~m}$. At each site, physicochemical water parameters $(\mathrm{pH}$, water temperature, dissolved oxygen and conductivity) were recorded and water samples were collected for the analysis of biological oxygen demand $\left(\mathrm{BOD}_{5}\right)$ and nutrients $\left(\mathrm{NO}_{3}-\mathrm{N}, \mathrm{NO}_{2}-\mathrm{N}, \mathrm{NH}_{3}-\mathrm{N}, \mathrm{NH}_{4}-\mathrm{N}\right.$, and $\left.\mathrm{PO}_{4}-\mathrm{P}\right)$ following APHA (1985) or a photochemical method with the Nova 400 Analyzer by Merck. The Habitat Modification Score (HMS) of the River Habitat Survey (Raven et al., 1998) was estimated for each site to evaluate habitat modifications.

Benthic invertebrates were sampled by wading along the riverbanks and/or the riverbed using a $250 \times 230 \mathrm{~mm}$ D-shaped pond $(0.9 \mathrm{~mm}$ mesh size, EN 27828:1994) according to the semiquantitative 3-min kick/sweep method (Armitage and Hogger, 1994) plus $1 \mathrm{~min}$ when bank vegetation existed (Wright, 2000; Kemitzoglou, 2004). During the 3-min sampling, all available microhabitats were 


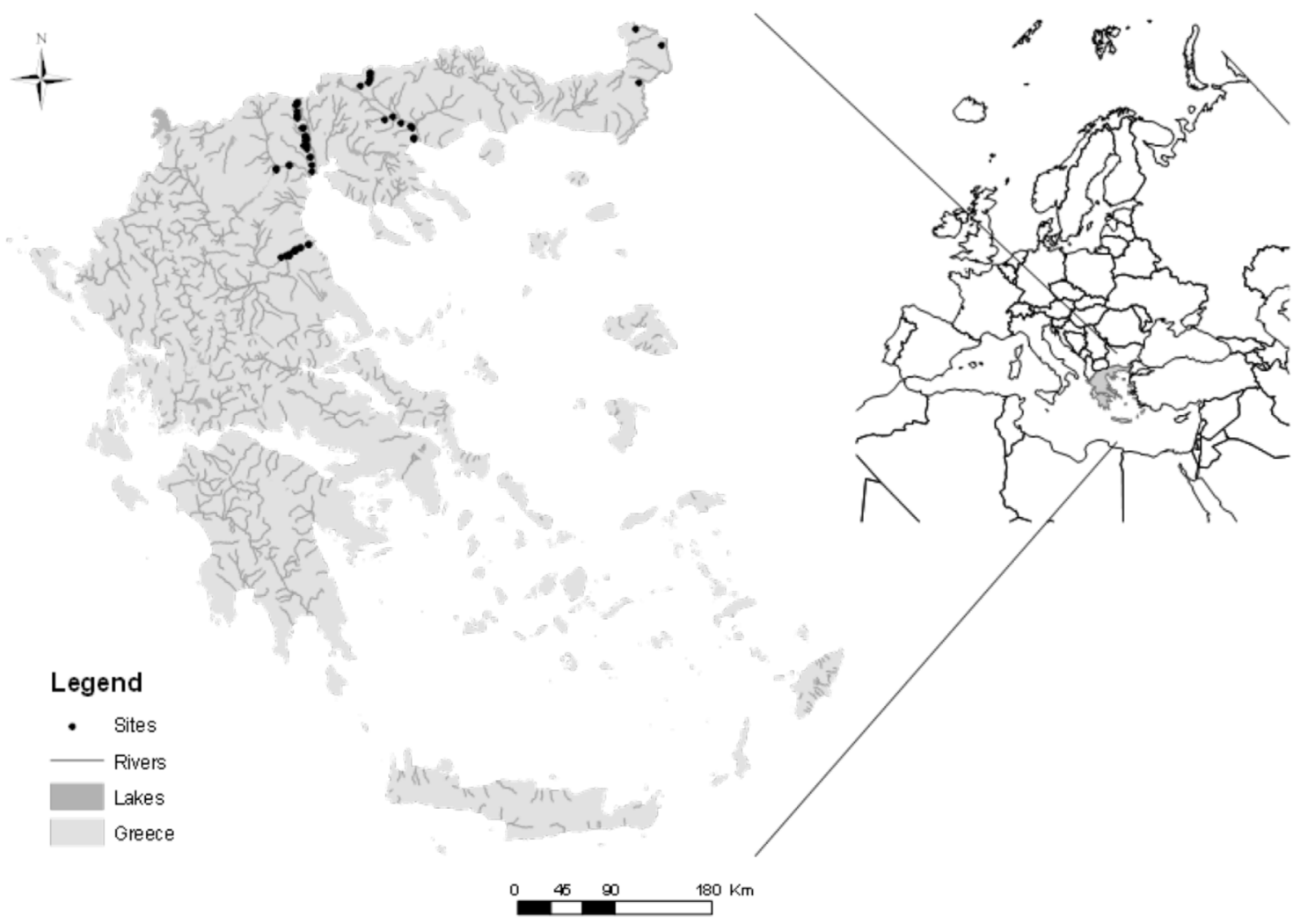

Fig. 1. Location of the 53 sampling sites at very large Greek rivers used in this study.

covered proportionally. Benthic invertebrates were preserved in $70-75 \%$ alcohol and identified to family level (except for the taxa Ancylus, Ostracoda, Hydracarina, Aranae, and Oligochaeta apart from Tubificidae) in the laboratory, including an estimation of their relative abundance. Subsampling was not applied.

\subsubsection{XGIG IC database}

Data used in the very large river IC exercise were delivered by 16 MSs participating in the exercise for Continental rivers (i.e., Austria, Belgium, Bulgaria, Croatia, Czech Republic, Estonia, Germany, Hungary, Latvia, Lithuania, The Netherlands, Poland, Romania, Slovakia, Slovenia, and Spain). These data were sampled within national WFD monitoring programs, covering 727 invertebrate samples and supporting environmental information at 279 sampling sites of very large rivers. The biological data used in the completed IC exercise covered the abundance and taxonomical composition of benthic invertebrate communities, which were sampled and processed according to national standards and used to quantify the Ecological Quality Ratio (EQR), i.e., the river type-specific ratio between the reference and observed values.

Samples were taken between 1997 and 2013. The MSs assessed each biological sample they provided, delivering an EQR score according to their national assessment method to be intercalibrated. The environmental data provided by the MSs included river name, national river type, name of water body and sampling site, altitude, upstream catchment area and location (latitude, longitude) of sampling site, ecoregion, alkalinity type, flow regime, and discharge.

The pressure data used to quantify the anthropogenic stressors acting at the sampling site covered eight hydromorphological parameters from Pont et al. (2009), categorized into two to four levels (Tab. 1). Parameter values were derived from national expert judgment, validated centrally using satellite images for the parameters channelization, riparian vegetation alteration, and navigation intensity (Bechter et al., 2018). Physicochemical pressures included annual average water concentrations of $\mathrm{NO}_{3}-\mathrm{N}$ and $\mathrm{PO}_{4}-\mathrm{P}$, transformed into values ranging from 1 to 4 to allow for quantification similar to the hydromorphological parameters.

\subsection{Greek assessment method}

The STAR_ICMi (Buffagni et al., 2006) was used to classify the ecological status of very large Greek rivers. This index includes six normalized and weighted metrics: ASPT, $\log _{10}($ sel_EPTD+1), 1-GOLD, number of EPT families, total number of families, and Shannon-Wiener diversity index. The index results in five classes of ecological status based on the benthic invertebrate community.

\subsubsection{Validating the pressure-response relationship}

The pressure-response relationship of the STAR_ICMi was validated considering the HMS, the hydromorphological metrics of CAPi (i.e., channelization, riparian vegetation, hydropeaking, and impoundment), the nutrient concentrations, 
Table 1. Pressure parameters and levels for the calculation of the Combined Abiotic Pressure index (CAPi) (Birk et al., 2016 based on Pont et al., 2009).

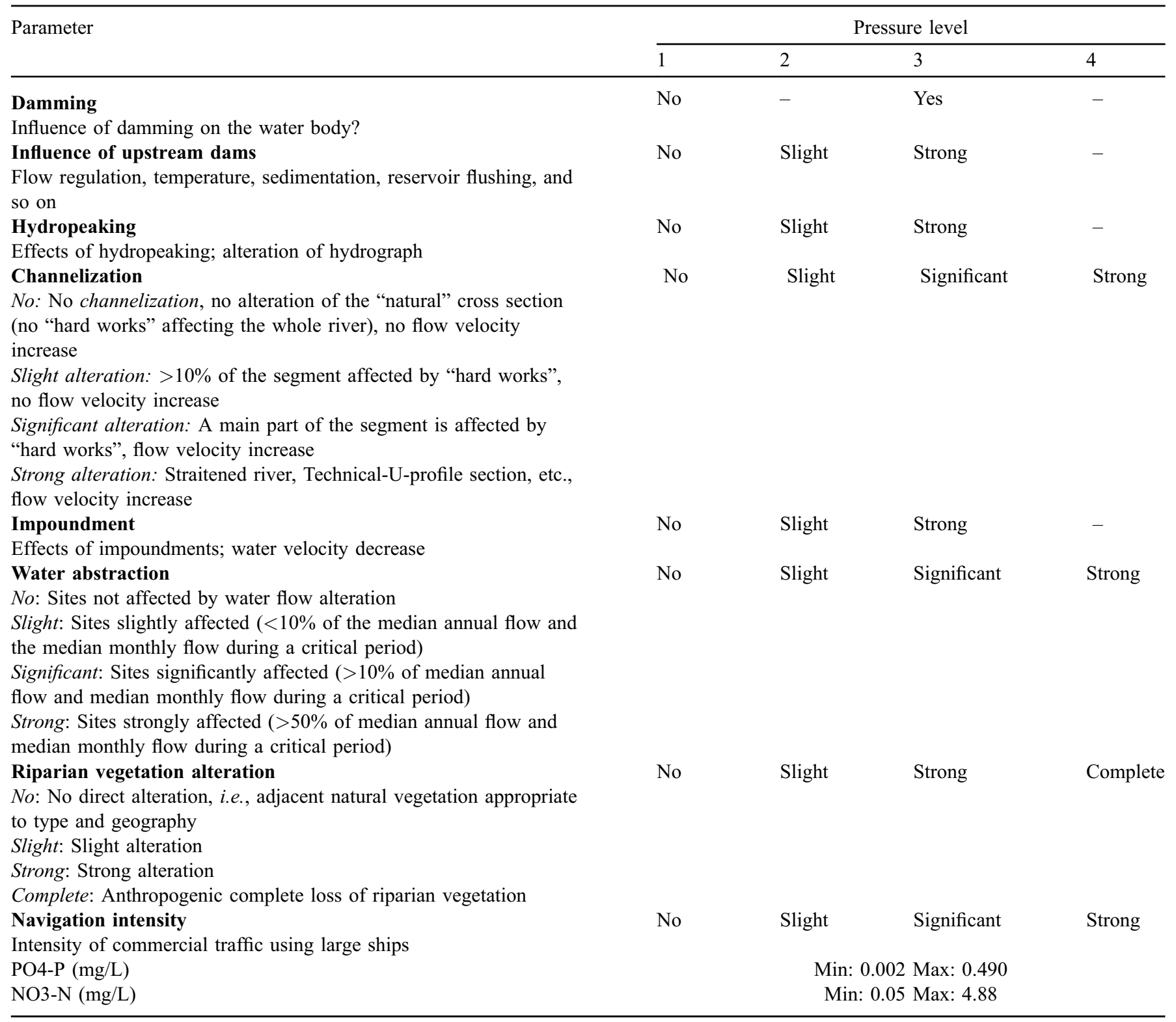

$\mathrm{BOD}_{5}$, dissolved oxygen, and various catchment land uses (e.g., extensive agricultural areas, intensive agricultural areas, and urban areas) in accordance with Corine Land Cover (2012). The validation was done by linear regression analysis with above-mentioned pressure parameters as independent variables and STAR_ICMi as dependent variable, using the software STATISTICA 13 (StatSoft Inc., 2015).

\subsubsection{Defining reference conditions and setting class boundaries}

Reference sites were absent in very large rivers and thus reference sites from large rivers (Mediterranean river type R-M3: large rivers with a catchment area of 1,000 $10,000 \mathrm{~km}^{2}$ ) were selected. Their selection was based on the hydromorphological and physicochemical criteria proposed by Feio et al. (2014) and their biological quality according to the Hellenic Evaluation System (HES; Artemiadou and Lazaridou, 2005); the value of SemiHES had to be $>4.0$, classifying the site in at least good ecological status.

To define the HG boundary of the STAR_ICMi, the 25 th percentile value from the reference samples was used. The range between zero value and HG boundary was then divided into four equal parts (quarters). The lower value of the first quarter (from the top) was set as the GM boundary.

\subsection{Intercalibration process}

\subsubsection{Calculating CAPi and IC index}

The CAPi amalgamates seven hydromorphological and two physicochemical variables (see Tab. 1). The biological IC 
M. Lazaridou et al.: Knowl. Manag. Aquat. Ecosyst. 2018, 419, 50

Table 2. Component metrics composing the IC index for the intercalibration of very large rivers (Birk et al., 2016).

\begin{tabular}{ll}
\hline Metric & Description \\
\hline EPT_HK\% & Percentage of EPT (Ephemeroptera + Plecoptera + Trichoptera as \% abundance classes) \\
No_EPTCBO & Number of EPTCBO taxa (Ephemeroptera + Plecoptera + Trichoptera + Coleoptera + Bivalvia + Odonata) \\
No_Tricho & Number of Trichoptera taxa \\
Potamal_ges\% & Preference for zonation type potamal $(\%$ individuals $)$ \\
AKA_HK\% & Preference for microhabitat akal $(\%$ abundance classes) \\
Pfil\% & Percentage feeding type passive filter feeders $(\%$ individuals $)$ \\
\hline
\end{tabular}

Table 3. Regression coefficients and anchor values (for metric normalization) obtained from the completed IC exercise. The regression equation is Metric $=$ slope $* \mathrm{CAPi}+$ intercept.

\begin{tabular}{|c|c|c|c|c|}
\hline \multirow[b]{2}{*}{ Metric } & \multicolumn{2}{|c|}{ Coefficients for linear regression } & \multicolumn{2}{|c|}{ Anchor values } \\
\hline & Slope & Intercept & Value for $\mathrm{EQR}=1$ & Value for $\mathrm{EQR}=0$ \\
\hline EPT_HK (\%) & -15.24 & 47.33 & 38.94 & 1.03 \\
\hline No_EPTCBO & -7.45 & 22.40 & 16.72 & 0.00 \\
\hline No_Tricho & -2.31 & 7.27 & 5.89 & -0.33 \\
\hline Potamal_ges (\%) & 2.82 & 44.29 & 28.38 & 71.63 \\
\hline Aka_HK (\%) & -2.08 & 9.08 & 17.96 & 1.33 \\
\hline Pfil (\%) & -2.80 & 9.05 & 16.38 & -5.59 \\
\hline
\end{tabular}

index was calculated as an arithmetic mean of the six component metrics (Tab. 2) after standardization through benchmarking and normalization. All metrics were computed using the ASTERICS software (Version 4.0.4; Wageningen Software Labs, 2005).

\subsubsection{Benchmarking approach}

The following procedure was adopted for the benchmark standardization of the component metrics and the STAR_ICMi:

Step 1: Linear regression between CAPi $(x)$ and each component metric $(y)$ derived from Greek data. For each metric, a linear regression based on the Greek data was plotted along with the regression line obtained for this metric from the completed XGIG IC exercise (Tab. 3).

Step 2: Comparison between regression lines fitted (i) on Greek data and (ii) on global data from the completed IC exercise.

Step 3: Offset calculation. The $y$-distance of the regression line fitted on Greek data to the line fitted on IC data was determined. For each component metric separately, this value specified the "offset," i.e., how different is the biological assessment $(y)$ at the same level of CAPi $(x)$ for the Greek data compared to the IC data (which included samples of all other countries participating in the IC exercise). This offset was subtracted from the Greek regression equation to fit the Greek line to the global regression. Component metrics subtracted by the offset yielded the "benchmark-standardized" metrics.

Step 4: The "benchmark-standardized" metric values were normalized in order to get values between 0 and 1, using anchor points (Tab. 3).

Step 5: The IC index was calculated by averaging the six benchmark-standardized and normalized metrics.

\subsubsection{Fitting the Greek classification to the IC results}

In order to fit the Greek assessment method into the completed IC exercise, the HG and GM boundaries had to be compared and harmonized with the "Global Mean View" obtained in the IC exercise (i.e., the average of the national good status boundaries expressed in units of the IC index). The main principle was that the deviation (=bias) of the Greek boundaries from the "Global Mean View" representing the HG or GM boundaries intercalibrated in the completed IC exercise must be $\leq 25 \%$, respectively (Willby et al., 2014).

\subsection{Describing the biological communities at good and less than good ecological status}

Similarity percentage analysis (SIMPER) was performed to describe the benthic invertebrate communities at high, good, and less than good ecological status according to the intercalibrated Greek classification. Statistical analysis was performed using the Primer v6 software (Clarke and Gorley, 2006) with a cutoff of $90 \%$.

\section{Results}

\subsection{Greek assessment method}

The STAR_ICMi was significantly correlated to pressures, i.e., channelization $(r=-0.30, p<0.05)$, riparian vegetation $(r=0.42, p<0.05)$, and organic pollution: $\mathrm{NO}_{3}-\mathrm{N}(r=-0.21$, $p<0.05)$ and $\mathrm{PO}_{4}-\mathrm{P}(r=-0.19, p<0.05)$. It was also significantly correlated with the CAPi $(r=-0.26, p<0.05)$. The HESY 2 showed low pressure-response relationships and thus was excluded from the IC exercise. 
Table 4. Mean and median values for the STAR_ICMi and its component metrics from three Greek reference sites (seven reference samples) of river type R-M3.

\begin{tabular}{lll}
\hline Metric / Index & Mean value & Median value \\
\hline ASPT-2 & 4.89 & 4.55 \\
$\log _{10}($ Sel EPTD +1) & 2.22 & 2.10 \\
1 -GOLD & 0.85 & 0.91 \\
EPT & 11.6 & 11 \\
$N$-families & 25.6 & 27 \\
Shannon-Wiener index & 1.97 & 1.89 \\
STAR_ICMi & 1.03 & 1.00 \\
\hline
\end{tabular}

ASPT: Average Score per Taxon, $\log _{10}$ (Sel EPTD): $\log _{10}$ (Sum of Heptageniidae, Ephemeridae, Leptophlebiidae, Brachycentridae, Goeridae, Polycentropodidae, Limnephilidae, Odontoceridae, Dolichopodidae, Stratyomidae, Dixidae, Empididae, Athericidae and Nemouridae), 1-GOLD: 1-(relative abundance of Gastropoda, Oligochaeta and Diptera), EPT: Sum of Ephemeroptera, Plecoptera and Trichoptera families, $N$-families: Sum of all families.

Three sites (including seven samples) belonging to the river type R-M3 were selected as reference sites for the definition of reference values for the assessment metrics of very large rivers. The mean and the median values of the STAR ICMi and its component metrics, derived from these three reference sites, are presented in Table 4 . The respective class boundaries of the Greek methods are shown in Table 5.

\subsection{Intercalibration process}

The CAPi obtained from the Greek data ranged from 1.25 to 2.89 , with the minimum value (indicating low pressure levels) recorded in river Pinios and the maximum value recorded in river Axios. The values of the IC index ranged from 0.25 to 0.95 .

In the first step of the analysis, the relationship between CAPi and each component metric of the IC index was established by ordinary least squares regression to prepare for the benchmark standardization (Fig. 2). When comparing the relationships gained from the Greek data with those of the completed XGIG IC exercise, the regression lines were not always parallel. Thus, the CAPi value estimated from the corresponding GM boundary value of the STAR_ICMi was selected as the point to calculate the $y$-distance (=offset): $\mathrm{CAPi}=1.88$, obtained according to the formula $\mathrm{CAPi}=$ $-0.48 \times($ STAR_ICMi $)+2.21\left(R^{2}=0.07, p<0.05, n=113\right)$. This procedure followed the approach of Buffagni et al., 2016. On this basis, the offsets for the individual component metrics of the IC index were determined for the benchmark standardization (Tab. 6).

After the six component metrics were benchmarkstandardized and normalized, they were averaged to calculate the final IC index, yielding a linear relationship $R^{2}=0.18$ (Fig. 3). Using the same approach employed to benchmarkstandardize the component metrics of the IC index, we also benchmark-standardized the EQR of the STAR ICMi against the final IC index (Fig. 4a). In this case, the point to derive
Table 5. Ecological Quality Ratios (EQR) of ecological status class boundaries for the STAR_ICMi in Greek very large rivers.

\begin{tabular}{ll}
\hline Class boundaries & EQR \\
\hline Reference & $\geq 1.00$ \\
High-good & $\geq 0.92-0.69<$ \\
Good-moderate & $\geq 0.69-0.46<$ \\
Moderate-poor & $\geq 0.46-0.23<$ \\
Poor-bad & $\leq 0.23$ \\
\hline
\end{tabular}

offset values was the GM boundary (0.69) of the STAR_ICMi. Thus, the offset correction (observed metric values) and the slope correction (dividing the observed values by a divisor) were made in STAR_ICMi bs values (Fig. 4b). Specifically, the following equation was applied: STAR_ICMi bs $=0.75 \times$ STAR_ICMi +0.07 (Tab. 7). Figure 5 presents the linear regression of the benchmark-standardized STAR_ICMi against the IC index.

This regression allowed to translate the Greek EQR values of the good status boundaries into values of the IC index. The bias for both boundaries was $>25 \%$, and it was thus necessary to adjust these boundaries (Tab. 8). The adjusted class boundaries and the harmonized values are presented in Table 9.

\subsection{Describing the biological communities at high, good, and less than good ecological status}

Only one sample was classified in high ecological status and consisted mainly of Ephemerellidae (45\% contribution), Baetidae (14\%), and Oligoneuriidae (14\%). At good status (11 samples), the average similarity of samples was $46 \%$ and assemblages were mainly represented by Baetidae (17\%), Chironomidae (14\%), Hydropsychidae (13\%), Caenidae (11\%), Heptageniidae (10\%), and Ephemerellidae (8\%). Samples classified in less than good status $(n=101)$ had an average similarity of $34 \%$ and consisted mostly of Chironomidae (32\%), Baetidae (16\%), Oligochaeta (13\%), Gammaridae $(10 \%)$, and Caenidae $(9.6 \%)$.

\section{Discussion}

\subsection{The Greek classification method for very large rivers}

This study initially aimed at adopting a WFD-compliant assessment method using benthic invertebrates for further use to classify the ecological status of very large rivers in Greece. The multimetric index STAR_ICMi was selected as the most appropriate one, since it showed pressure-response relationships to a number of pressures $\left(\mathrm{NO}_{3}-\mathrm{N}, \mathrm{PO}_{4}-\mathrm{P}, \mathrm{CAPi}\right)$. The Hellenic Evaluation System 2 (Lazaridou et al., 2018), however, which was successfully intercalibrated for other river types in Greece (R-M1, R-M2, R-M4, R-M5), did not qualify for the classification of very large rivers, because it did not respond statistically to pressures at this river type. This could be attributed to the specific characteristics of HESY2 (e.g., its habitat standardization; Lazaridou et al., 2018), which require a strict adherence to the multihabitat sampling 

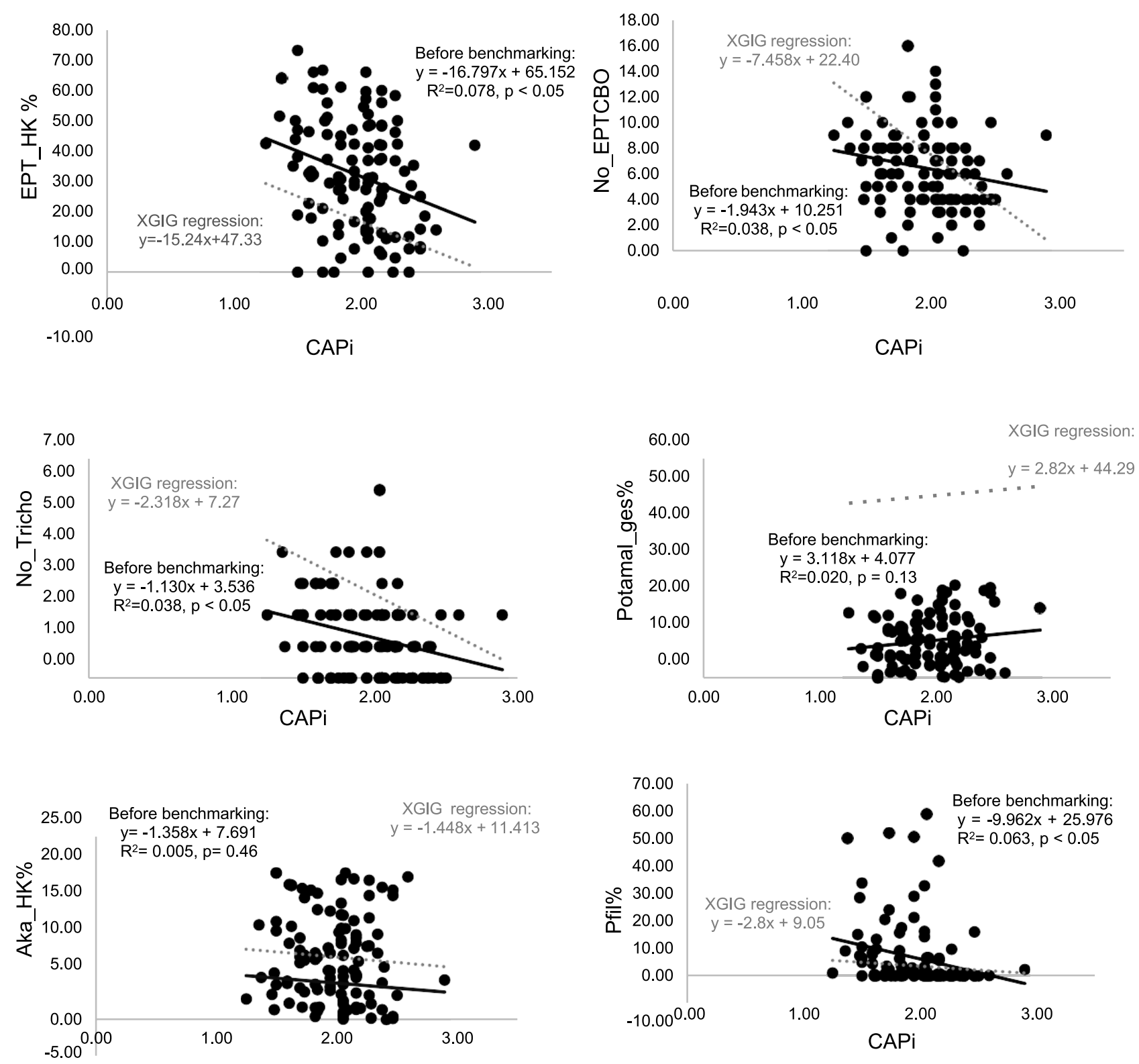

CAPi

Fig. 2. Linear regression between component metrics of the IC index and the Combined Abiotic Pressure index (CAPi) before benchmarking (black solid line), including the regression line obtained in the completed XGIG intercalibration exercise (gray dotted line).

Table 6. Offsets in component metrics of IC index derived from benchmark-standardizing the component metrics against the CAPi.

\begin{tabular}{ll}
\hline Metrics & Offsets \\
\hline EPT_HK\% & -14.90 \\
No_EPTCBO & 1.80 \\
No_Tricho & 1.52 \\
Potamal_ges\% & 39.65 \\
AKA_HK\% & -3.52 \\
Pfil\% & -3.46 \\
\hline
\end{tabular}

protocol. In very large rivers, however, samplings were mainly conducted at the riverbanks, and thus habitat standardization was not applicable.

Some MSs, including Greece, did not participate in the official IC exercise due to the lack of an assessment method (as in this case) or due to failure to intercalibrate it (e.g., lacking relationship with the IC index). Thus, Willby et al. (2014) provided a "cook-book" to fit new or updated assessment methods into the completed IC exercises under the requirements of the WFD. Undoubtedly, this document helped many MSs, especially from Southern and Eastern Europe, to harmonize their class boundaries. In practice, the 


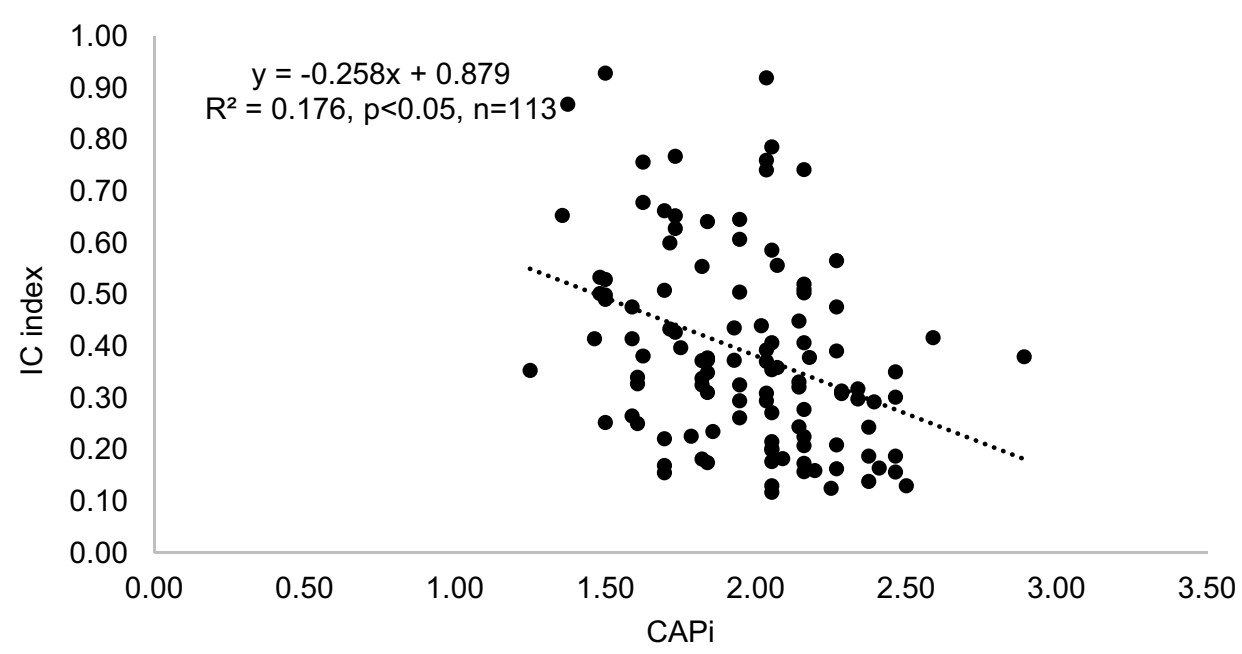

Fig. 3. Pressure-response relationship relating the CAPi to benchmark-standardized IC index.

fit-in process has proven to be thoroughly demanding and difficult. However, the selected assessment method was successfully intercalibrated using the above procedure. Thus, Greece may apply restoration measures for the very large rivers when a water body is assessed with an ecological status less than good.

\subsection{Biological sampling and identification at very large rivers}

The first step in all monitoring programs is the design of the sampling strategy, as it has to deliver representative information about the ecological status of water bodies in space and time (EC, 2011). In very large lowland rivers, the sampling design is a difficult task, because representatives from various invertebrate taxonomic groups, which colonize different physical habitats depending on depth, substrate type, discharge, and water level fluctuations, need to be covered by the sampling design. Thus, several methods of data acquisition were used in Europe, differing in sampling technique and frequency, number of replicates, and sampled area (Birk et al., 2012a). The XGIG IC exercise was constricted to the main channel habitats and related slackwaters as the most representative areas for very large rivers. Overall, $11 \mathrm{MSs}$ sampled both the main channel and the riverbanks from very large rivers, 5 MSs (Bulgaria, Croatia, Estonia, Latvia, and Sweden) sampled only the riverbanks, 2 (Belgium and Finland) only the main channel, and 1 MS (Austria) all available habitats (Birk et al., 2016). Our study also utilized samples from riverbanks, since similar ecological status was observed between artificial substrate samples placed in the river course, and the kick net samples taken from the littoral zones of the riverbanks (Chatzinikolaou et al., 2005). Csányi et al. (2012) confirmed our sampling strategy by showing that more abundant invertebrate communities existed in the littoral zone than in the deeper riverbed of the Danube river.

Subsampling was not applied during the identification of the biological material in very large Greek rivers because it might introduce a source of uncertainty on the water body classification (Spitale, 2017).

\subsection{Reference conditions and boundary setting to assess very large rivers}

One crucial issue related to WFD implementation is the establishment of reference conditions (EC, 2000). Very large rivers are affected by a significant number of human pressures, some of which are already acting for centuries, like discharges of industrial and municipal waste water, hydropower generation, navigation, water extraction, reclamation of agricultural land in the floodplains, and flood protection works. The selection of reference sites is thus challenging and problematic; usually a pressure gradient ranging from undisturbed (pristine areas) to highly degraded conditions is rare in most of the MSs (Birk et al., 2016). Therefore, other approaches to establish reference conditions were adopted (Birk et al., 2012b), e.g., using least disturbed sites or modeling approaches, in which near-natural reference values were extrapolated from gradients across more or less disturbed sites. These approaches hold the risk of an inaccurate and incomparable definition of reference values. Due to the absence of reference sites also in the very large rivers of Greece, we selected reference sites from rivers with catchment sizes less than $10,000 \mathrm{~km}^{2}$ (type R-M3) based on harmonized criteria proposed by Feio et al. (2014). This option represented a pragmatic approach to the challenge of lacking reference sites in very large rivers.

Ecological class boundary thresholds were established with different approaches for each MS participating in XGIG IC exercise. Most of them used equidistant division of the EQR gradient (like Slovakia and the Netherlands), combined with boundary setting using best available sites (like Croatia and Finland), and boundary calibration against pre-classified river sites (like Hungary and Latvia) (Birk et al., 2016). In Greece, the HG boundary threshold was set by reference sites from slightly smaller rivers following the criteria of Feio et al. (2014). After intercalibrating the STAR_ICMi index as presented in this article, the HG (1.01) and GM (0.73) boundaries for Greece showed the highest values in comparison to all other MS that participated in the IC exercise, except for Romania with boundary positions equally high (HG: 1.05, GM: 0.71). 

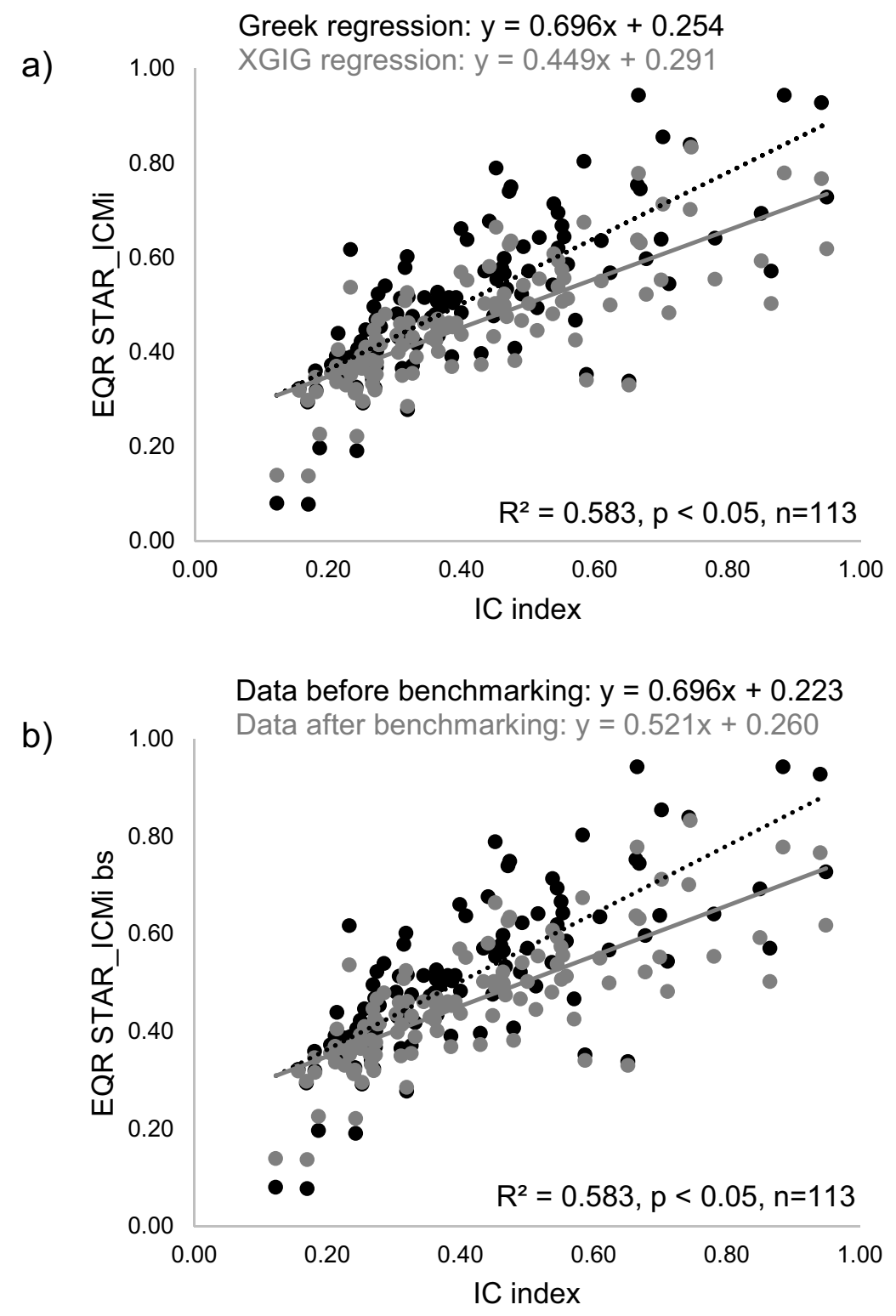

Fig. 4. Linear regression of the benchmark-standardized IC index against (a) the unstandardized and (b) the benchmark-standardized Greek EQR values ( $n=113$ samples). Regression lines and equations represent the relationship of the completed XGIG IC exercise (grey solid line), and the relationships of the unstandardized (black dashed line) and benchmark-standardized (black solid line) STAR_ICMi bs based on the Greek data.

Table 7. Calculation details of Greek boundaries to the XGIG "Global Mean View" of IC index.

\begin{tabular}{llll}
\hline Status boundary & EQR STAR_ICMi & $\begin{array}{l}\text { Benchmark-standardized } \\
(\text { EQR STAR_ICMi bs) })^{1}\end{array}$ & Global mean view \\
\hline Reference & 1.00 & 0.82 & 1.09 \\
High-good & 0.92 & 0.76 & 0.80 \\
Good-moderate & 0.69 & 0.59 & 0.61 \\
Moderate-poor & 0.46 & 0.42 & 0.43 \\
Poor-bad & 0.23 & 0.24 & 0.27 \\
\hline
\end{tabular}

${ }^{1}$ EQR STAR_ICMi bs $=0.75 *$ EQR STAR_ICMi +0.07 


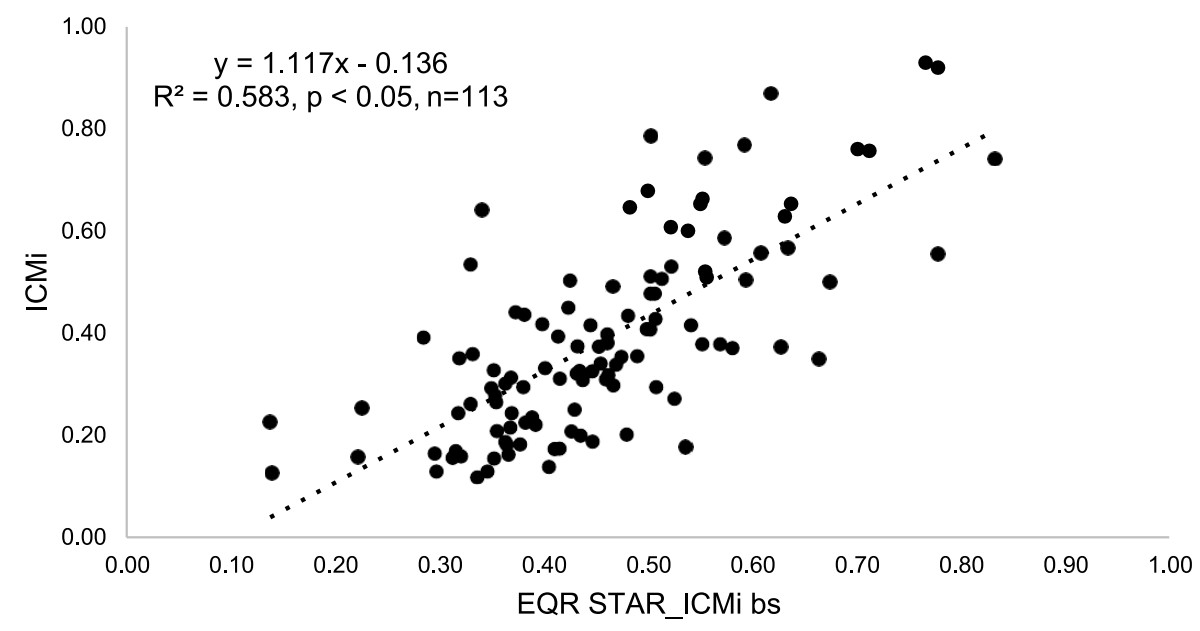

Fig. 5. Linear regression of benchmark-standardized Greek EQRs (EQR STAR_ICMi) against the IC index.

Table 8. Translated national boundaries of ecological status and related boundary bias before and after boundary harmonization.

\begin{tabular}{|c|c|c|c|c|}
\hline Status boundary & Translated into IC index (ICMi bs) ${ }^{1}$ & Difference & Class width & Boundary bias \\
\hline & \multicolumn{4}{|c|}{ Before harmonization } \\
\hline Reference & 0.78 & & & \\
\hline High-good & 0.71 & -0.08 & 0.07 & -1.23 \\
\hline Good-moderate & 0.52 & -0.09 & 0.19 & -0.49 \\
\hline Moderate-poor & 0.33 & & & \\
\hline \multirow[t]{2}{*}{ Poor-bad } & 0.13 & & & \\
\hline & \multicolumn{4}{|c|}{ After harmonization } \\
\hline Reference & 0.81 & & & \\
\hline High-good & 0.79 & -0.01 & 0.02 & -0.25 \\
\hline Good-moderate & 0.56 & -0.05 & 0.23 & -0.24 \\
\hline Moderate-poor & 0.33 & & & \\
\hline Poor-bad & 0.13 & & & \\
\hline
\end{tabular}

${ }^{1}$ ICMi_bs $=1.12 *$ EQR STAR_ICMi bs -0.14

Table 9. Final (harmonized) class boundaries of the IC index, the benchmark standardized (bs) and the original STAR_ICMi for very large rivers in Greece.

\begin{tabular}{llll}
\hline Status boundary & IC index & STAR_ICMi bs & $\begin{array}{l}\text { STAR_ICMi } \\
\text { original }\end{array}$ \\
\hline Reference & 0.81 & 0.85 & 1.04 \\
High-good & 0.79 & 0.83 & 1.01 \\
Good-moderate & 0.56 & 0.62 & 0.73 \\
Moderate-poor & 0.39 & 0.47 & 0.53 \\
Poor-bad & 0.23 & 0.33 & 0.35 \\
\hline
\end{tabular}

\subsection{Validating the pressure-response relationship at very large rivers}

The cumulative effect of anthropogenic pressures in the catchments disguises the variation between river types due to different abiotic characteristics (e.g., geology; Skoulikidis,
2009). Consequently, pressure-response relationships are difficult to establish because biological assemblages are additionally affected by multiple natural factors. The STAR_ICMi mainly correlated with the effects of pressures in Mediterranean rivers (like hydromorphological degradation, organic pollution) (Erba et al., 2015; Karaouzas et al., 2015; Lazaridou and Ntislidou, 2015; Buffagni et al., 2016). In the completed IC exercise, 6 out of 19 MSs could not establish a clear pressure-response relationship due to either too few disturbed sites (Estonia, Finland, Norway, and Sweden) or too few undisturbed sites (Belgium, the Netherlands) to establish an effective pressure gradient. These MSs thus assumed significant pressure-response relationships of their assessment methods at very large rivers, drawing from evidence gained at smaller rivers. Other MSs that participated in the completed IC exercise demonstrated significant relationships for organic/nutrient pollution $(32 \%)$, hydromorphological alterations (11\%), or both (21\%) (Birk et al., 2016). In our case, STAR_ICMi index showed a better response to hydromorphological alterations (i.e., channelization, riparian 
vegetation) than to organic pollution, probably due to the sampling design.

\subsection{Biological communities in very large rivers}

It is worth noticing the predominance of Chironomidae in all ecological classes in very large rivers across MSs, with relative abundances ranging from 16 to $39 \%$ across status classes. In Greece, however, the relative abundance of Chironomidae rises from $4 \%$ in sites at high and good ecological status to $31 \%$ in sites at less than good status: the chironomid abundance increases as the status worsens. This pattern is only shared by the Italian very large rivers, pointing at comparable river types between these two Mediterranean countries.

Furthermore, the SIMPER analysis showed that mainly the presence of oligochaets and gammarids accounted for the differences between the good and less than good status classes. This was in line with the classifications of all other MSs. Oligochaeta are considered pollution-tolerant taxa and have low scores in most national assessment methods (e.g., HESY2, BMWP, and IBMWP). Gammaridae occur in all Greek river types with permanent flow (R-M1, R-M2, R-M3, and R-M4) and have particularly higher abundances in rivers at moderate status (Lazaridou et al., 2018). They are further considered as tolerant to moderate pollution levels according to HESY2 (Lazaridou et al., 2018) and other national indices, e.g., BMWP (Armitage et al., 1983) and IBMWP (Alba-Tercedor et al., 2002).

\section{Conclusion}

The STAR ICMi multimetric index takes into consideration the tolerance, the abundance, and the diversity/richness of the biological community, and addresses the general degradation of combined pressures. It is composed of metrics considering the main features of the benthic community required by WFD. The fitting of the STAR ICMi to the results of the XGIG very large river intercalibration exercise was successful, and the STAR ICMi will now be officially applied for the classification of the ecological status of very large rivers in Greece. It will be further verified once the results of the forthcoming National Monitoring Program (2018-2023) are available.

Acknowledgements. This study has been prepared in the framework of the Greek National Water Monitoring Network for rivers implemented by HCMR, according to the Joint Ministerial Decision 140384/2011. The Network is supervised by the Directorate for the Protection and Management of Water Resources of the Special Secretariat for Waters, Ministry of Environment and Energy. The data used in this study come from the Acts MIS. 371010, 371138, 371140, 371144, and 371145 of the Operational Program "Environment and Sustainable Development" financed by the European Regional Development Fund and studies done in Central and Northern Greece by the School of Biology, Aristotle University of Thessaloniki.

\section{References}

Alba-Tercedor J, Jáimez-Cuéllar P, Álvarez M, Avilés J, Bonada N, Casas J, Mellado A, Ortega M, Pardo I, Prat N, Rieradevall M, Robles S, Sáinz-Cantero CE, Sánchez-Ortega A, Suárez ML, Toro M, VidalAbarca MR, Vivas S, Zamora-Muñoz C. 2002. Caracterización del estado ecológico de ríos mediterrâneos ibéricos mediante el índice IBMWP (antes BMWP'). Limnetica 21: 175-185.

APHA. 1985. Standard Methods for the Examination of Water and Wastewater, 16th ed. Washington: American Public Association, $541 \mathrm{p}$.

Armitage PD, Hogger J. 1994. Invertebrates ecology and survey. In: Ward D, Holmes N, Jose P, eds. The New Rivers and Wildlife Handbook. Bedfordshire: Sandy RSPB, pp. 151-159.

Armitage PD, Moss D, Wright JF, Furse MT. 1983. The performance of a new biological water quality score system based on macroinvertebrates over a wide range of unpolluted running water sites. Water Res 17: 333-347.

Artemiadou V, Lazaridou M. 2005. Evaluation score and interpretation index for the ecological quality of running waters in Central and Northern Hellas. Environ Monit Assess 110: 1-40.

Bechter T, Baumann K, Birk S, Bolik F, Graf W, Pletterbauer F. 2018. LaRiMo - A simple and efficient GIS-based approach for largescale morphological assessment of large European rivers. Sci Total Environ 628-629: 1191-1199.

Bennett C, Owen R, Birk S, Buffagni A, Erba S, Mengin N, MurrayBligh J, Ofenböck G, Pardo I, van de Bund W, Wagner F, Wasson JG. 2011. Bringing European river quality into line: an exercise to intercalibrate macro-invertebrate classification methods. Hydrobiologia 667: 31-48.

Birk S, Korte T, Hering D. 2006. Intercalibration of assessment methods for macrophytes in lowland streams: direct comparison and analysis of common metrics. Hydrobiologia 566: 417-430.

Birk S, Bonne W, Borja A, Brucet S, Courrat A, Poikane S, van de Bund W, Zampoukas N, Hering D. 2012a. Three hundred ways to assess Europe's surface waters: an almost complete overview of biological methods to implement the Water Framework Directive. Ecol Indic 18: 31-41.

Birk S, van Kouwen L, Willby N. 2012b. Harmonising the bioassessment of large rivers in the absence of near-natural reference conditions - a case study of the Danube River. Freshw Biol 57: 1716-1732.

Birk S, Willby NJ, Kelly M, Bonne W, Borja A, Poikane S, van de Bund W. 2013. Intercalibrating classifications of ecological status: Europe's quest for common management objectives for aquatic ecosystems. Sci Total Environ 454-455: 490-499.

Birk S, Böhmer J, Schöll F. 2016. XGIG Large River Intercalibration Exercise - Milestone 6 Report - Intercalibrating the national classifications of ecological status for very large rivers in Europe Biological Quality Element: Benthic Invertebrates - Version 2, 228 p.

Buffagni A, Erba S, Cazzola M, Murray-Bligh J, Soszka H, Genoni P. 2006. The STAR common metrics approach to the WFD intercalibration process: full application for small, lowland rivers in three European countries. Hydrobiologia 566: 379-399.

Buffagni A, Erba S, Furse MT. 2007. A simple procedure to harmonize class boundaries of assessment systems at the panEuropean scale. Environ Sci Policy 10: 709-724.

Buffagni A, Cazzola M, Erba S, Verzino L, Bordin F, Galbiati L, Moruzzi E, Balestrini R. 2016. Intercalibrating the Italian classification of ecological status based on aquatic macroinvertebrates in very large rivers. CNR-IRSA, Brugherio, $48 \mathrm{p}$.

Chatzinikolaou Y, Findik O, Ilia G, Lazaridou M. 2005. Comparative study of two benthic macroinvertebrate sampling methods: the 
3-minute kick-and-sweep sampling method versus artificial substrate colonization in a large Mediterranean river in central Greece, in Fourth Symposium for European Freshwater Sciences (SEFS4) Krakow, Poland, pp. 22-26.

Clarke KR, Gorley RN. 2006. PRIMER V6: user manual-tutorial. Plymouth Marine Laboratory, $190 \mathrm{p}$.

Csányi B, Szekeres J, György AI, Szalóky Z, Falka I. 2012. Methodology of macroinvertebrate survey on large rivers: a case study on the Romanian Lower Danube. Water Res Manage 2: $25-40$.

EC 2000. Directive 2000/60/EC of the European Parliament and of the Council of 23 October 2000 Establishing a Framework for Community Action in the Field of Water Policy. Official Journal of the European Communities L327, $72 \mathrm{p}$.

EC 2005. Guidance on the Intercalibration Process 2004-2006. Official Publications of the European Communities, Luxembourg, $31 \mathrm{p}$.

EC 2011. Guidance Document on the Intercalibration Process 20082011. European Communities, 103 p.

EC 2012. Commission Staff Working Document, European Overview (1/2) Accompanying the Document: "Report from the Commission to the European Parliament and the Council on the Implementation of the Water Framework Directive (2000/ 60/EC) River Basin Management Plans," Brussels, 670 p.

EC 2015. Procedure to fit new or updated classification methods to the results of a completed intercalibration exercise. European Union, $33 \mathrm{p}$.

Erba S, Furse MT, Balestrini R, Christodoulides A, Ofenböck T, van de Bund W, Wasson J-G, Buffagni A. 2009. The validation of common European class boundaries for river benthic macroinvertebrates to facilitate the intercalibration process of the Water Framework Directive. Hydrobiologia 633: 17-31.

Erba S, Pace G, Demartini D, Di Pasquale D, Dörflinger G, Buffagni A. 2015. Land use at the reach scale as a major determinant for benthic invertebrate community in Mediterranean rivers of Cyprus. Ecol Indic 48: 477-491.

Feio MJ, Aguiar FC, Almeida SFP, Ferreira J, Ferreira MT, Elias C, Serra SRQ, Buffagni A, Cambra J, Chauvin C, Delmas F, Dörflinger G, Erba S, Flor N, Ferréol M, Gem M, Mancini L, Manolaki P, Marcheggiani S, Minciardi MR, Munné A, Papastergiadou E, Prat N, Puccinelli C, Rosebery J, Sabater S, Ciadamidaro S, Tornés E, Tziortzis I, Urbanič G, Vieira C. 2014. Least disturbed condition for European Mediterranean rivers. Sci Total Environ 476: 745-756.
Karaouzas I, Skoulikidis N, Andriopoulou A, Koutsodimou M, Kouvarda T, Gritzalis K. 2015. Effects of multiple stressors on the ecological status of a Mediterranean intermittent river. 11th Panhellenic Symposium on Oceanography and Fisheries, Mytilene, Lesvos Island, Greece, 681-684.

Kemitzoglou D. 2004. The effectiveness of the semi-quantitative sampling method using benthic macroinvertebrates. Dissertation Thesis, Aristotle University of Thessaloniki, Greece, $86 \mathrm{p}$.

Lazaridou M, Ntislidou C. 2015. Macroinvertebrate Assemblages and Biological Status of Rivers in Northern and Central Greece. In: Skoulikidis N, Dimitriou E, Karaouzas I, eds. The Rivers of Greece. The Handbook of Environmental Chemistry, Heidelberg, 28: $327-354$.

Lazaridou M, Ntislidou C, Karaouzas I, Skoulikidis N. 2018. Harmonization of a new assessment method for estimating the ecological quality status of Greek running waters. Ecol Indic 84: 683-694.

Pont D, Beers M, Buijse T, Delaigue O, Ferreira T, Jepsen N, Kovac V, Schabuss M, Segurado P, Schütz C, Vehanen T. 2009. River Fish Intercalibration Group WFD Intercalibration Phase 2 - Milestone 1 Report, $48 \mathrm{p}$

Raven P, Holmes N, Dawson F, Everard M. 1998. Quality assessment using River Habitat Survey data. Aquatic Conserv 8: 477-499.

Skoulikidis N. 2009. The environmental state of rivers in the Balkans - a review within the DPSIR framework. Sci Total Environ 407: 2501-2516.

Spitale D. 2017. Performance of the STAR_ICMi macroinvertebrate index and implications for classification and biomonitoring of rivers. Knowl Manag Aquat Ecosyst 418: 20.

StatSoft Inc. 2015. STATISTICA (data analysis software system), version 13. www.statsoft.com.

Wageningen Software Labs 2005. ASTERICS - AQEM-STAR Ecological River Classification System. Version 4. 0.3, July 2013.

Willby N, Birk S, Poikane S, van de Bund W. 2014. Water Framework Directive Intercalibration Manual. Procedure to fit new or updated classification methods to the results of a completed intercalibration. Ispra, Italy, $28 \mathrm{p}$.

Wright JF. 2000. An introduction to RIVPACS. In: Wright JF, Sutcliffe DW, Furse MT, eds. Assessing the Biological Quality of Fresh Waters: RIVPACS and Other Techniques. Freshwater Biological Association, Ambleside, pp. 1-24.

Cite this article as: Lazaridou M, Ntislidou C, Karaouzas I, Skoulikidis N, Birk S. 2018. Harmonization of the assessment method for classifying the ecological quality status of very large Greek rivers. Knowl. Manag. Aquat. Ecosyst., 419, 50. 